\title{
Laparoscopic Sentinel Lymph Node Versus Hyperextensive Pelvic Dissection for Staging Clinically Localized Prostate Carcinoma: A Prospective Study of 200 Patients
}

\author{
Caroline Rousseau ${ }^{1,2}$, Thierry Rousseau ${ }^{3}$, Loïc Campion ${ }^{4}$, Jacques Lacoste ${ }^{3}$, Geneviève Aillet ${ }^{5}$, Eric Potiron ${ }^{3}$, \\ Marie Lacombe ${ }^{1}$, Georges Le Coguic ${ }^{3}$, Cédric Mathieu ${ }^{1}$, and Françoise Kraeber-Bodéré1,2,6 \\ ${ }^{I}$ Nuclear Medicine Unit, ICO Gauducheau Cancer Center, Saint Herblain, France; ${ }^{2}$ CRCNA INSERM U892, Institut de recherche \\ thérapeutique de l'Université, Nantes, France; ${ }^{3}$ Urologic Clinic Nantes-Atlantis, Saint-Herblain, France; ${ }^{4}$ Statistics Unit, ICO \\ Gauducheau Cancer Center, Saint Herblain, France; ${ }^{5}$ Anatomopathology Unit, Institut d'Histopathologie, Nantes, France; \\ and ${ }^{6}$ Nuclear Medicine Unit, University Hospital, Nantes, France
}

\begin{abstract}
Lymph node metastasis is an important prognostic factor in prostate cancer (PC). The aim of this prospective study was to validate, through laparoscopic surgery, the accuracy of the isotopic sentinel lymph node (SLN) technique correlated with hyperextensive pelvic resection (extended pelvic lymphadenectomy dissection) in patients with localized PC, candidates for local curative treatment. Methods: A transrectal ultrasound-guided injection of $99 \mathrm{mTc}$-sulfur rhenium colloid $(0.3$ $\mathrm{mL} / 100 \mathrm{MBq}$ ) in each prostatic lobe was performed the day before surgery. Detection was performed intraoperatively with a laparoscopic probe, followed by extensive resection. SLN counts were performed in vivo and confirmed ex vivo. Histologic analysis was performed by hematoxylin-phloxine-safran staining, followed by immunohistochemistry if the SLN was free of metastasis. Results: Two hundred three patients with PC at intermediate or high risk of lymph node metastases were included. The intraoperative detection rate was 96\% (195/203). Thirty-five patients had lymph node metastases, 19 only in the SLN. The false-negative rate was $8.5 \%$ (3/35). Unilateral surgical SLN detection did not validate bilateral pelvic lymph node status, and extended pelvic lymphadenectomy dissection was necessary on the opposite side of detection to minimize the false-negative rate $(2.8 \%$ [1/35]). A significant metastatic sentinel invasion in the common iliac region existed (9.3\%) but was always associated with other metastatic node areas. The internal iliac region was the primary metastatic site (40.7\%). Finally, this series invalidated any justification for a standard or limited dissection, which would have missed $51.9 \%$ and $74.1 \%$ of lymph node metastases, respectively. Conclusion: The radioisotope SLN identification method up to the common iliac region is successful to identify sentinel nodes during laparoscopic surgery per hemipelvis to be acceptably considered as an isolated procedure and should be validated for intermediate- and high-risk patients.
\end{abstract}

Key Words: prostate cancer; laparoscopic surgery; sentinel lymph node; hyperextended pelvic lymph node dissection

J Nucl Med 2014; 55:753-758

DOI: 10.2967/jnumed.113.129023

\footnotetext{
Received Jul. 10, 2013; revision accepted Nov. 13, 2013.

For correspondence or reprints contact: Caroline Rousseau, ICO Gauducheau Cancer Center, Boulevard Monod, 44805 Saint Herblain Cedex, France.

E-mail: caroline.rousseau@ico.unicancer.fr

Published online Mar. 31, 2014.

COPYRIGHT (c) 2014 by the Society of Nuclear Medicine and Molecular Imaging, Inc.
}

$\mathbf{T}$ he prognosis of prostate cancer (PC) is directly linked to tumor size and lymph node histologic status. A strong association between nodal status and distant metastases in PC has been demonstrated (1). Lymph node staging is important for prognosis and treatment (2).

Despite advances in imaging techniques, extended pelvic lymphadenectomy dissection (ePLND) appears to be the most reliable method for lymph node staging of PC patients at intermediate or high risk of metastasis $(3,4)$. In fact, several studies showed that the lymph node invasion rate in PC is higher when ePLND is performed than when nonextended PLND is (5-7). However, quantitating the ePLND area is at the heart of considerable debate in urology today, primarily because of the required surgical time and the potential for complications $(6,8)$.

In this context, the sentinel lymph node (SLN) technique, which assumes that the pathologic status of the SLN reflects the status of other pathologic regional lymph nodes, appears relevant (9), improves staging accuracy, and decreases the morbidity of ePLND $(10,11)$.

In the same context, nomograms based on initial clinical and pathologic characteristics have been developed to predict the risk of nodal involvement in PC patients, thus identifying groups with a low lymph node invasion risk who might be safely spared from undergoing ePLND (12).

The aim of this prospective study was to validate, through laparoscopic surgery, the accuracy of the isotopic SLN technique correlated with ePLND in patients with localized PC, candidates for local curative treatment (prostatectomy or external radiotherapy).

\section{MATERIALS AND METHODS}

Two hundred three consecutive PC patients with an intermediate or high risk of lymph node metastases according to D'Amico were eligible between June 2008 and July 2012 in our center (13). The sentinel node lymphadenectomy took place at the same time as hyperextensive lymph node dissection for patients chosen for treatment with radical prostatectomy or with external radiotherapy in order to not disregard a possible variable lymphatic drainage according to the findings observed in preliminary series of patients, as reported in previous publications $(14,15)$. The exclusion criteria were previous pelvic surgery, resection of prostate or inguinal hernia, prior hormonal treatment, and history of recent prostatitis. The first group of patients $(n=24)$ was enrolled in a prospective study approved by the ethics committee (Comité de Protection des 
Personnes, Nantes), and a signed informed consent form was obtained. The other patients received written information, but the requirement for signed consent was waived. The characteristics of the population are summarized in Table 1. Among the 154 patients with prostatectomy, histologic analysis of the prostatectomy specimens revealed an increased Gleason score in 72 patients (46.7\%), resulting in $10.5 \%$ of preoperative patients being incorrectly classified as D'Amico 2.

\section{Lymphoscintigraphy}

The day before surgery, patients received 2 injections of $100 \mathrm{MBq}$ of ${ }^{99 \mathrm{~m}} \mathrm{Tc}$-rhenium sulfide (Nanocis; IBA France) in a volume of $0.3 \mathrm{~mL}$ in each prostate lobe under endorectal ultrasound guidance. The mean injected activity of ${ }^{99 m} \mathrm{Tc}$-rhenium sulfide was $248.5 \pm 63.9 \mathrm{MBq}$. The radiochemical purity of the radiopharmaceutical was greater than $95 \%$. Antibiotic prophylaxis was administered $1 \mathrm{~d}$ before isotopic injection in all patients. A SPECT/CT image centered on the abdominopelvic region was acquired with a hybrid camera (SymbiaT2; Siemens) $2 \mathrm{~h}$

TABLE 1

Patient Characteristics

\begin{tabular}{|c|c|}
\hline Characteristic & $n=203$ \\
\hline Median age (y) & 64 (range, 44-78) \\
\hline \multicolumn{2}{|l|}{ Type of surgery } \\
\hline SLN + ePLND & $49(24.2 \%)$ \\
\hline SLN + ePLND + prostatectomy & $154(75.8 \%)$ \\
\hline \multicolumn{2}{|l|}{ D'Amico score } \\
\hline 2 & $163(80 \%)$ \\
\hline 3 & $40(20 \%)$ \\
\hline \multicolumn{2}{|l|}{ Tumor stage } \\
\hline $\mathrm{T} 1$ & $72(35.3 \%)$ \\
\hline $\mathrm{T} 2 \mathrm{a}$ & $90(44.6 \%)$ \\
\hline $\mathrm{T} 2 \mathrm{~b}$ & $28(13.7 \%)$ \\
\hline T3a & $13(6.4 \%)$ \\
\hline $\begin{array}{l}\text { Median initial prostate-specific } \\
\text { antigen }(\mathrm{ng} / \mathrm{mL})\end{array}$ & 8 (range, 2-130) \\
\hline$<10$ & 115 \\
\hline $10-19$ & 60 \\
\hline $20-49$ & 22 \\
\hline $50-99$ & 5 \\
\hline$>100$ & 1 \\
\hline \multicolumn{2}{|l|}{ Gleason biopsy } \\
\hline 6 & 43 \\
\hline $3+4$ & 105 \\
\hline $4+3$ & 39 \\
\hline $4+4$ & 11 \\
\hline $4+5$ & 5 \\
\hline \multicolumn{2}{|l|}{ No. of cores taken } \\
\hline Mean & 19.74 \\
\hline Median & 18 \\
\hline Range & $6-28$ \\
\hline \multicolumn{2}{|l|}{ Percentages of positive cores (\%) } \\
\hline Mean & 39.1 \\
\hline Median & 36 \\
\hline Range & $4-100$ \\
\hline \multicolumn{2}{|l|}{ Gleason after surgery (154 patients) } \\
\hline 6 & 37 \\
\hline $3+4$ & 88 \\
\hline $4+3$ & 20 \\
\hline $4+4$ & 5 \\
\hline $4+5$ & 4 \\
\hline \multicolumn{2}{|l|}{ Histopathologic stage } \\
\hline pT2 & 78 \\
\hline рT3a & 51 \\
\hline pT3b & 25 \\
\hline
\end{tabular}

after isotopic injection. The CT scan was multislice and spiral and had the following characteristics: $130 \mathrm{kV}$, adapting the amperage depending on the patient's morphology (CARE Dose 4D; Siemens), and 3-mm-thick sections. The SPECT acquisition included 64 images of 30-s duration, each with a $256 \times 256$ matrix. SLNs were defined visually as hot spots on scintigraphic images, and fusion images were used to localize SLNs in relation to anatomic structures.

\section{Surgical Technique}

Three urologists performed the laparoscopic SLN procedure and the ePLND. The patient was placed supine in a Trendelenburg position. Four ports were introduced after insufflation of the abdominal cavity: a 10-mm umbilical port for the optics, a $10-\mathrm{mm}$ port on the left, another 5 -mm on the right, and a final 12-mm suprapubic port about $3 \mathrm{~cm}$ above the pubis for the implementation of the detection probe. A laparoscopic probe (Gamma SUP; Clerad) was used. The electronic module was expressed in counts per second (cps) and collected the average count of $5 \mathrm{~s}$.

The first surgical procedure was identification of lymph node area, including beyond the ureters (the common iliac area) to the aortic bifurcation (Fig. 1). For the obturator fossa, the resection borders were along the middle of the external iliac vein laterally, the superior rim of the pubic bone distally, the obturator nerve medially, and the iliac bifurcation proximally. The external iliac region was limited laterally by the genitofemoral nerve, distally by the inguinal ligament, and proximally by the iliac bifurcation. The internal iliac region comprised the lymphatic tissue medial to the obturator nerve, including the nodes along the internal iliac artery up to the iliac bifurcation proximally. The common iliac region was limited by the aortic bifurcation, bifurcation of the internal/external iliac arteries, psoas muscle and genitofemoral nerve, and the medial border common iliac artery.

Then, the surgeon identified background noise to measure the activity at the radiocolloid injection sites, by systematic recording of the activity emitted from the right and left prostatic lobes. Afterward, the SLNs were counted and tracked in the various pelvic and iliac lymph node chains, possibly presacral or promontory, methodically keeping the detector probe in contact with the lymph node area for $5 \mathrm{~s}$.

The urologist performed the counting in vivo after excision to ensure that the removal of the SLN was complete. Finally, an extended bilateral pelvic lymph node dissection, including the entire pelvic lymph node area (obturator fossa, external iliac lymph nodes, and internal iliac nodes, including beyond the ureters at the level of the common iliac area until the aortic bifurcation), was conducted. This dissection is considered the dissection of reference and the gold standard and has determined the false-negative $(\mathrm{FN})$ rate retrospectively.

Radical prostatectomy was performed according to the case at the same surgery time.

Besides counting in vivo during the surgical procedure, ex vivo counting on a table away from the patient was performed immediately after excision of the SLN. We considered this ex vivo counting measurement method the most sensitive and the most specific to isolate the SLN from background. Indeed, away from the patient, the background noise was low, so the lymph nodes were considered SLNs as soon as the count was greater than 5 .

\section{Histology}

SLNs were measured macroscopically and embedded in paraffin. Three-millimeter-thick serial sections were stained with hematoxylin-phloxine-saffron. Microscopic serial sections (6 levels of 150$\mu \mathrm{m}$ sections) were obtained when macroscopic serial sections revealed no metastasis. These sections were studied by standard hematoxylin-phloxine-saffron staining, and by immunohistochemistry with the anti-KL1, to detect possible micrometastases. 


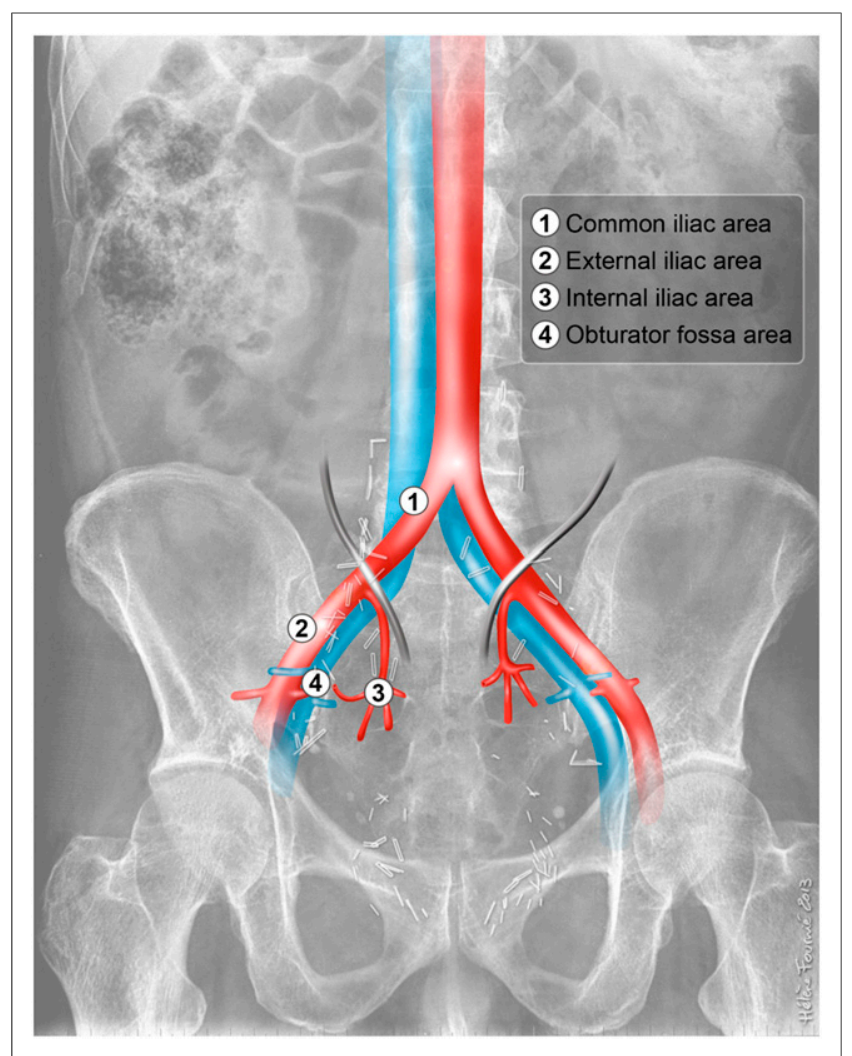

FIGURE 1. Postoperative radiologic appearance shows limits of SLN detection and ePLND.

\section{Statistical Analysis}

The quantitative parameters were described as mean \pm SD (with median and range) and compared between groups using the parametric ANOVA test or the Student $t$ test. Nonparametric tests (Kruskal-Wallis or Mann-Whitney) were used for small samples. Qualitative parameters were described by their modality distribution and compared with the $\chi^{2}$ test (Pearson) or Fisher exact test when numbers were small. The correlation between quantitative variables was calculated using the Spearman correlation test. All calculations were performed with Stata (Special Edition 10.1; StataCorp). All tests were performed bilaterally in formulation with a limit of significance set at $5 \%(P<0.05)$.

\section{RESULTS}

\section{Lymphoscintigraphy}

The intraprostatic injection after prophylactic antibiotic therapy was well tolerated in all patients.

SPECT/CT identified SLNs in 191 of 203 patients (94\%), and 6 SPECT/CT examinations failed to detect SLNs in the first part of the series. SLN SPECT/CT identification was seen on both sides in 159 patients $(83.2 \%)$ and on one side in $32(16.8 \%)$, with an intraoperative bilateral detection for 8 of them. A total number of 1,122 SLNs were detected by SPECT/CT $(5.5 \pm 3.1$ per patient $)$. SLNs were detected in the common iliac region in $31.1 \%$ of cases, in the external iliac in $15.1 \%$, in the internal iliac in $19.8 \%$, in obturator fossa in $17.7 \%$, and in the promontory and presacral area in $6.3 \%$. Lymphoscintigraphy was especially better for the detection of SLN localized in the 3 areas far from the prostate (external iliac, common iliac, and presacral) in relation to the 2 areas near the prostate injection sites (obturator fossa or internal iliac) $(P<0.0001)$.

\section{Intraoperative Detection}

Intraoperative detection was performed on average $19 \pm 1.8 \mathrm{~h}$ after injection of the radiopharmaceutical. The median probe count for in vivo SLNs was 264 (range, 10-3,558) and ex vivo, 89 (range, 2-1,930). One or more SLNs were detected in 195 of 203 patients $(96 \%)$, in a total of 1,153 removed SLNs. For 4 of the 8 patients for whom intraoperative detection failed, SPECT/CT did not highlight any SLN. The detection rate was $86.7 \%$ (176/ $203)$ in the right hemipelvis and $74.4 \%$ in the left $(151 / 203)(P=$ 0.002). A total of 1,155 SLNs were removed, $5.6 \pm 3.7$ SLNs per patient (mean $\pm \mathrm{SD}$ ). SLNs were detected in the common iliac region in $19.5 \%$ of cases, $25.2 \%$ in the external iliac, $26.1 \%$ in the internal iliac, $27 \%$ in obturator fossa, and $2.2 \%$ in the promontory and presacral area. In the 32 patients in whom SPECT/ CT showed unilateral drainage, $10(31 \%)$ patients had intraoperative detection highlighting SLNs on the side not seen on scintigraphy, 3 of them with metastatic SLNs. The extended systematic lymphadenectomy collected a total of 4,527 non-SLNs, giving a mean of $28.32 \pm 10.22$ lymph nodes per patient.

The adverse event rate was $4 \%(8 / 203)$ including 1 injury to the small branch internal iliac vein clipped during the surgical procedure, 1 ureteral injury with a perioperative anastomosis, and 7 postoperative lymphoceles. These events were expected within the framework of extended pelvic lymphadenectomy and could not be specifically considered complications of the SLN procedure. All cases were completed laparoscopically without recourse to open surgery. The duration of SLN detection associated with extensive pelvic lymphadenectomy was on average $108 \pm 33.1 \mathrm{~min}$.

\section{Histologic Analysis}

For all types of nodes (SLN and non-SLN), histologic examination revealed macro- and micrometastases in 35 patients (17.2\%) and was limited to the SLNs in 19 of them (54.2\%). In 8 patients $(23 \%)$, lymph node invasion was observed in a sentinel node in the form of micrometastases diagnosed only by immunohistochemistry. In these 35 patients, 6 of them had unilateral PC, and in half of them, lymph node metastases were found in the contralateral side. The characteristics of the 35 patients with metastatic nodes are shown in Table 2. Three patients without SLN metastases had metastatic non-SLNs. The FN rate was therefore $8.5 \%$ (3/35). Therefore, the sensitivity of SLN biopsy for node metastasis detection was 32 of 35 (91.4\%; 95\% confidence interval, 76.9-98.2). Of the 171 patients with negative SLNs, 168 had a negative non-SLN, yielding a negative predictive value of 98.2\% (95\% confidence interval, 94.9-99.6). The accuracy of SLN technique was $89.05 \%$ (95\% confidence interval, 83.9-93.0). The 14 patients who were positive on SLN and non-SLN biopsy had a bilateral PC and a higher percentage of positive prostate cores $(72.6 \pm 29.8)(P<0.01)$. Five of them had a unilateral SLN detection, and for all of them on the contralateral side, only metastatic non-SLNs were found. If the rules to validate the technique of SLN for a patient were if a side is without detected SLN, ePLND required the FN rate of the technique to be only $2.8 \%$ (1/35). Topographic distribution of SLN and non-SLN metastasis is shown in Figure 2. The 3 areas (obturator fossa, external iliac, and internal iliac) were equivalent in terms of SLN surgical detection. In contrast, most metastatic SLNs were located in the internal iliac region $(P=0.02)$. The obturator fossa and the external iliac were the areas in which we found the most metastatic non-SLNs. Hierarchically, the common iliac area was slightly less detected than the other areas but was a metastatic site in $9.3 \%$ of patients yet was 
TABLE 2

Characteristics of Patients with Metastases in SLNs or Non-SLNs

\begin{tabular}{|c|c|c|c|c|c|c|c|c|c|c|c|c|}
\hline $\begin{array}{c}\text { Patient } \\
\text { no. }\end{array}$ & $\begin{array}{c}\text { Gleason } \\
\text { score }\end{array}$ & $\begin{array}{c}\text { Prostate- } \\
\text { specific antigen } \\
(\mathrm{ng} / \mathrm{mL})\end{array}$ & $\begin{array}{l}\text { D'Amico } \\
\text { score }\end{array}$ & $\begin{array}{c}\text { \% positive } \\
\text { biopsies }\end{array}$ & $\begin{array}{l}\text { \% lymph node } \\
\text { invasion } \\
\text { according } \\
\text { to Memorial } \\
\text { Sloan-Kettering } \\
\text { Cancer Center } \\
\text { nomogram (2) }\end{array}$ & $\begin{array}{l}\text { \% lymph } \\
\text { node } \\
\text { invasion } \\
\text { according } \\
\text { to Briganti } \\
\text { nomogram } \\
(12)\end{array}$ & $\begin{array}{l}\text { No. of } \\
\text { LNs in } \\
\text { ePLND }\end{array}$ & $\begin{array}{l}\text { No. } \\
\text { and } \\
\text { sites } \\
\text { of } \\
\text { positive } \\
\text { SLNs }\end{array}$ & & $\begin{array}{c}\text { Size of } \\
\text { metastases } \\
(\mathrm{mm})\end{array}$ & $\begin{array}{c}\text { No. and } \\
\text { sites of } \\
\text { positive } \\
\text { non- } \\
\text { SLNs }\end{array}$ & \\
\hline 1 & $3+4$ & 33 & 3 & 100 & 7.8 & 20 & 34 & $2 / 15$ & obt & 7 and 6 & $1 / 19$ & ei \\
\hline 2 & $4+3$ & 27 & 3 & 18 & 6.7 & 7 & 25 & $1 / 6$ & ii & 6 & $0 / 19$ & - \\
\hline 3 & 8 & 6 & 3 & 46 & 4.6 & 17 & 26 & $2 / 3$ & obt, ei & 5 and 6 & $1 / 23$ & ei \\
\hline 4 & $4+3$ & 15 & 2 & 65 & 4.4 & 22 & 31 & $4 / 12$ & $\begin{array}{l}\text { obt, ii, } \\
\text { ci }\end{array}$ & $\begin{array}{c}3,8,5 \text {, and } \\
10\end{array}$ & $0 / 19$ & - \\
\hline 5 & 8 & 6 & 3 & 36 & 7.2 & 15 & 25 & $2 / 7$ & ii, ci & 0.22 and 3 & $2 / 18$ & ei, ii \\
\hline 6 & $3+4$ & 6 & 2 & 100 & 2.4 & 12 & 20 & $1 / 6$ & ii & 0.98 & $0 / 14$ & - \\
\hline 7 & $3+4$ & 9 & 2 & 100 & 4.9 & 21 & 19 & $2 / 4$ & obt, ii & 3 and 5 & $2 / 15$ & obt \\
\hline 8 & $4+3$ & 22 & 3 & 100 & 24.2 & 81 & 33 & $1 / 3$ & ii & 2 & $0 / 30$ & - \\
\hline 9 & $3+4$ & 60 & 3 & 82 & 18.9 & 28 & 22 & $0 / 6$ & - & - & $2 / 16$ & ei \\
\hline 10 & $4+3$ & 6 & 2 & 44 & 2.5 & 12 & 29 & $2 / 8$ & obt, ii & 2 and 3 & $0 / 21$ & - \\
\hline 11 & 6 & 10 & 2 & 75 & 1.9 & 6 & 39 & $0 / 1$ & - & - & $3 / 38$ & ei, ci \\
\hline 12 & $3+4$ & 8 & 2 & 100 & 2.9 & 19 & 31 & $1 / 11$ & ii & 5 & $0 / 20$ & - \\
\hline 13 & 8 & 130 & 3 & 47 & 30.3 & 40 & 18 & $2 / 5$ & ii & 1 and 3 & $4 / 13$ & $\begin{array}{l}\text { obt, } \\
\text { ii, ei }\end{array}$ \\
\hline 14 & $3+4$ & 8 & 3 & 100 & 4.6 & 20 & 30 & $2 / 5$ & ii, ei & 10 and 10 & $2 / 25$ & ii \\
\hline 15 & $4+3$ & 12 & 2 & 60 & 3.6 & 13 & 27 & $1 / 1$ & obt & 15 & $0 / 26$ & - \\
\hline 16 & $3+3$ & 5 & 2 & 61 & 6.8 & 19 & 19 & $1 / 6$ & ii & 30 & $2 / 13$ & obt \\
\hline 17 & $4+3$ & 12 & 2 & 74 & 3.7 & 27 & 23 & $4 / 8$ & ii, ei, ci & $\begin{array}{c}1.1,8,8 \\
\text { and } 15\end{array}$ & $3 / 15$ & $\mathrm{ci}$ \\
\hline 18 & $4+3$ & 6 & 3 & 47 & 4.0 & 14 & 23 & $1 / 5$ & obt & 10 & $0 / 18$ & - \\
\hline 19 & $4+3$ & 40 & 3 & 77 & 14.2 & 49 & 35 & $1 / 7$ & obt & 1 & $0 / 28$ & - \\
\hline 20 & $3+3$ & 3 & 2 & 44 & 1.2 & 3 & 31 & $1 / 7$ & ii & 4 & $0 / 24$ & - \\
\hline 21 & $3+4$ & 14 & 2 & 37 & 4.1 & 7 & 15 & $1 / 6$ & $\mathrm{ii}$ & 0.5 & $0 / 9$ & - \\
\hline 22 & $3+4$ & 30 & 3 & 40 & 7.5 & 10 & 15 & $4 / 4$ & $\begin{array}{l}\text { ei, ci, } \\
\text { prom }\end{array}$ & $\begin{array}{c}5,5,6, \text { and } \\
15\end{array}$ & $0 / 11$ & - \\
\hline 23 & $3+4$ & 26 & 3 & 100 & 6.7 & 33 & 18 & $2 / 4$ & ei, ei & 15 and 15 & $1 / 14$ & obt \\
\hline 24 & $3+4$ & 4 & 2 & 44 & 3.8 & 4 & 48 & $1 / 14$ & obt & 1.4 & $0 / 34$ & - \\
\hline 25 & $4+3$ & 15 & 2 & 25 & 2.7 & 18 & 31 & $1 / 12$ & obt & 1 & $0 / 19$ & - \\
\hline 26 & $4+3$ & 6 & 2 & 36 & 2.5 & 12 & 14 & $2 / 6$ & obt, ii & 0.5 and 10 & $0 / 8$ & - \\
\hline 27 & $3+4$ & 21 & 3 & 100 & 23.5 & 64 & 26 & $1 / 1$ & ii & 7 & $3 / 25$ & $\begin{array}{l}\text { obt, } \\
\text { ei, ei }\end{array}$ \\
\hline 28 & 8 & 6 & 3 & 90 & 86 & 40 & 21 & $2 / 3$ & obt, ii & 8 and 8 & $5 / 18$ & $\begin{array}{l}\text { ei, } \\
\text { obt }\end{array}$ \\
\hline 29 & $4+3$ & 14 & 2 & 27 & 4.1 & 12 & 17 & $1 / 4$ & ii & 2 & $0 / 13$ & - \\
\hline 30 & $3+4$ & 31 & 3 & 27 & 7.5 & 5 & 17 & $2 / 7$ & $\begin{array}{l}\text { obt, } \\
\text { obt }\end{array}$ & 1 and 1 & $0 / 10$ & - \\
\hline 31 & $4+5$ & 7 & 3 & 74 & 8.7 & 30 & 18 & $1 / 6$ & ei & 2 & $0 / 12$ & - \\
\hline 32 & 6 & 6 & 2 & 5 & 1.5 & $<2.5$ & 30 & $3 / 13$ & $\begin{array}{c}\text { obt, ii, } \\
\text { ei }\end{array}$ & $\begin{array}{c}5,5, \text { and } \\
10\end{array}$ & $1 / 17$ & ei \\
\hline 33 & $4+5$ & 11 & 3 & 45 & 3.5 & 7 & 27 & $0 / 3$ & - & - & $3 / 24$ & ii, ci \\
\hline 34 & $4+5$ & 3 & 3 & 42 & 6.3 & 13 & 13 & $1 / 4$ & ii & 6 & $0 / 9$ & - \\
\hline 35 & $3+4$ & 11 & 2 & 100 & 37.6 & 80 & 34 & $1 / 7$ & obt & 2.5 & $0 / 27$ & - \\
\hline
\end{tabular}

obt = obturator fossa; ii = internal iliac; ei = external iliac; ci = common iliac; prom = promontory.

always associated with other metastatic node areas. Limited dissection to the obturator fossa would have missed $73 \%$ of SLNs and $74.1 \%$ of metastatic SLNs. For a standard lymphadenectomy (obturator fossa and external iliac region), the percentages would have been $47.8 \%$ of the SLNs and $51.9 \%$ of metastatic SLNs.

\section{DISCUSSION}

This study confirms the diagnostic usefulness of SLN radiodetection in prostate cancer. Sensitivity per patient was $91.4 \%$, with a neg- ative predictive value of $98.2 \%$ and an accuracy of $89.05 \%$. These performances are very much equivalent to those obtained, recently, in cervical cancer, for which the sensitivity was $91.4 \%$ and negative predictive value was $98.2 \%$ (16). To our knowledge, this prospective study is the first to examine a large number of patients reporting a laparoscopic detection of SLNs in PC systematically associated with ePLND beyond the ureteral junction (17-27). Two major results can be highlighted. The first result is the importance of validating the technique of SLN detection not only per patient but especially per hemipelvis in order for the method to be considered acceptable as an isolated 


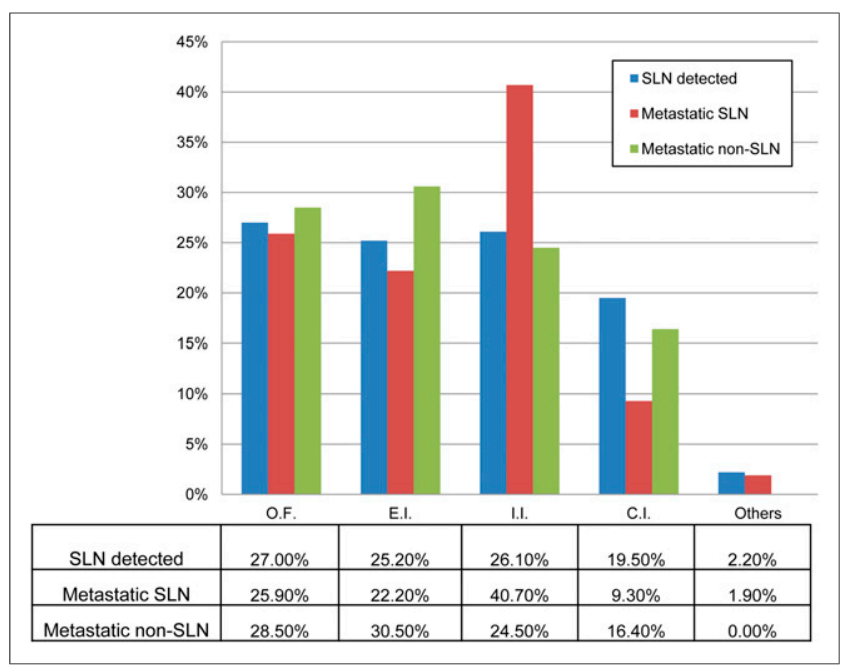

FIGURE 2. Comparison of SLN sites $(n=1,155)$, metastatic SLNs $(n=$ $54)$, or non-SLNs $(n=49)$ detected intraoperatively by probe in 195 patients.

procedure. And second, a significant metastatic SLN invasion in the common iliac region exists but never in isolation and reopens the debate about the extension of dissection and especially considering what the SLN technique can provide at the common iliac level.

The prostate, being a midline structure, should have bilateral drainage, and it is not possible to predict the preferential side of lymphatic drainage in this setting. Thus, ideally, at least one SLN should be studied on each side of the pelvis, and the SLN identification rate should be reported not only per patient but also per side. This approach is described for the SLNs in cervical cancer but not in PC, for which analysis is done per patient or per drainage area. When studies on this disease are revisited, detection rates, when interpreted per side, are lower, whereas FN rates, considering each hemipelvis in isolation, are improved (28). As we have seen in our study, the detection rate per side $(86.7 \%$ and $74.4 \%$ for right and left side, respectively) is lower than per patient $(96 \%)$, but the FN rate would be minimal, with $2.8 \%$ instead of $8.5 \%$ per patient. If the SLN procedure is performed without systematic lymphadenectomy, patients with unilaterally identified SLNs should undergo complete contralateral lymphadenectomy because ipsilateral SLN status does not represent nodal status in the contralateral hemipelvis. A negative SLN contralateral to a metastatic lymph node is not an FN. Neither does the detection of 1 SLN per patient represent a detection rate of $100 \%$. Rather, FNs and detection rates must be interpreted per side in order to be meaningful in terms of prognostication and patient outcome. With this minimal negative rate $(2.8 \%)$, we are below the limits set by international guidelines for breast cancer (29). In the guidelines of the European Association of Urology, the method of histologic detection of lymph node metastases, such as SPLND (PLND assisted by SLN technique), is regarded as suitable for lymph node staging in PC (30). Recently, Jeschke et al. proposed in PC a combination of intraoperative SLN isotope/fluorescence detection in a procedure reminiscent of double detection, which was the reference in breast cancer (31).

The second major strength of our study, which is in accordance with our preliminary study (15), is that a significant SLN proportion was scintigraphically detected $(19.5 \%)$ in the common iliac area and finally was metastatic $(9.3 \%)$. Unlike some reports, the common iliac area in our study appeared to be likely to harbor metastatic lymph nodes (SLN and non-SLN). Comparison of our study with that of Joniau et al. (27) showed with 371 SLNs removed (vs. 1,153 in our study), in all lymph node areas examined, 3 times fewer SLNs were detected in the common iliac area than in ours. This is consistent with what was reported by supporters of extended lymphadenectomy (4): when a high number of nodes were removed, the number of involved nodes increased. Although invasion of the common iliac area was never found in isolation in our study, this raises the question of interest of not achieving SLN detection in this area although the surgical approach is deemed difficult. For patients who receive only this technique in the future, surgically detected SLNs in this region will highlight extensive disease and may give information for salvage treatment if prostatespecific antigen increases in the future. Second, if the dissection becomes of therapeutic relevance as some suggest (29), the important goal will be to remove as many nodes as possible, with the priority being removal of all SLNs because they are subject to variable and atypical drainage, regardless of the nodal region. Moreover, SLN mapping has the potential for enhanced sensitivity in the detection of metastatic disease. Ultrastaging by serial sectioning is time-consuming and costly, but ideally within the limits of 4-6 SLNs because micrometastases are rarely identified using conventional pathology sectioning and staining. Furthermore, our study found that in $57 \%$ of cases the SLN is the only lymph node harboring metastatic disease and in $40 \%(14 / 35)$ of the cases these were micrometastases and for 9 of them only SLN micrometastases. Although the prognostic value of micrometastasis remains unclear in PC (32), if it is based on breast cancer data, for which SLN micrometastases are associated with an adverse impact on disease recurrence or survival (33), our patients may have received an ultrastratification benefit because they potentially have a worse prognosis than patients free of metastases.

In patients with one or more SLNs involved, a significant number of metastases are also located in non-SLNs (33). In our study, 12 of 35 patients (34.2\%) had a dual invasion (SLN and non-SLN). The benefit of the SLN technique for these patients could be to help find atypical drainage (29).

However, as described in the literature $(27,33)$, the internal iliac region is always the area most represented in terms of detection and metastatic status for SLNs.

Finally, this series corroborates the fact that the distribution of metastatic SLNs invalidates any justification for a standard or limited dissection. In the 35 metastatic patients in our study, $74.1 \%$ of metastatic SLNs were located outside the limited dissection (obturator fossa) and $51.9 \%$ outside the range of the external iliac and obturator fossa. Previous studies have shown between $30.0 \%$ and $72.7 \%$ of metastatic lymph nodes in addition to limited dissection and between $10.0 \%$ and $59.7 \%$, compared with standard laparoscopic dissection (18-20,22-26).

Regarding SLN anatomic distribution, there appears to be a large variability and extent of SLN anatomic distribution (11). Vermeeren et al. (24) have demonstrated in a previous study the value of SPECT/CT versus planar scintigraphy acquisition. Moreover, in our study, we observed a difference between the distribution of SLNs in SPECT/CT and intraoperatively—what had already been noted by Corvin et al. but less dramatically than in our study (20). The 2 prostate injection sites may explain the difference in detection of SLNs by SPECT/CT and in intraoperative detection: with SPECT/CT, the SLNs located at a distance from the prostate were significantly better individualized than those nearby. In contrast, during surgery, the SLNs near the prostate tend to be better located than those in the common iliac area because the periprostatic surgical approach is easier. 
Complications related to intraprostatic injection of tracer remain rare $(21,22,34)$. Some rare cases of prostatitis have been described $(23,25)$; however, none was detected in our study. Adverse events are relatively uncommon in SLN mapping, because in our series of SLNs explored laparoscopically, we observed a complication rate of $4 \%$, observed only during the ePLND and never during the detection of SLNs.

\section{CONCLUSION}

The radioisotope SLN identification method for the common iliac region is successful at identifying SLNs during laparoscopic surgery per hemipelvis and can feasibly be considered acceptable as an isolated procedure, with an intraoperative detection rate of $96 \%$ and an $\mathrm{FN}$ rate of $2.8 \%$. Our results demonstrate that SLN monitoring in intermediateand high-risk PC patients is a reliable procedure for nodal staging and can prevent unnecessary pelvic lymph node dissection.

\section{DISCLOSURE}

The costs of publication of this article were defrayed in part by the payment of page charges. Therefore, and solely to indicate this fact, this article is hereby marked "advertisement" in accordance with 18 USC section 1734 . No potential conflict of interest relevant to this article was reported.

\section{ACKNOWLEDGMENTS}

This study was given as an oral presentation at the European Nuclear Medicine Congress in Milan, 2012, and during the Highlights Session. It was also presented as a poster at the European Urology Congress in Milan, 2013, and was awarded the best poster prize in the Poster Session "How to optimize staging in prostate cancer."

\section{REFERENCES}

1. Bubendorf L, Schöpfer A, Wagner U, et al. Metastatic patterns of prostate cancer: an autopsy study of 1,589 patients. Hum Pathol. 2000;31:578-583.

2. Cheng L, Zincke H, Blute M, Bergstralh E, Scherer B, Bostwick D. Risk of prostate carcinoma death in patients with lymph node metastasis. Cancer. 2001;91:66-73.

3. Heidenreich A, Aus G, Bolla M, et al. EAU guidelines on prostate cancer. Eur Urol. 2008;53:68-80.

4. Briganti A, Chun FK, Salonia A, et al. Complications and other surgical outcomes associated with extended pelvic lymphadenectomy in men with localized prostate cancer. Eur Urol. 2006;50:1006-1013.

5. Masterson TA, Bianco FJ Jr., Vickers AJ, et al. The association between total and positive lymph node counts, and disease progression in clinically localized prostate cancer. J Urol. 2006;175:1320-1324.

6. Briganti A, Chun FK, Salonia A, et al. Critical assessment of ideal nodal yield at pelvic lymphadenectomy to accurately diagnose prostate cancer nodal metastasis in patients undergoing radical retropubic prostatectomy. Urology. 2007;69:147-151.

7. Heidenreich A, Ohlmann CH, Polyakov S. Anatomical extent of pelvic lymphadenectomy in patients undergoing radical prostatectomy. Eur Urol. 2007;52:29-37.

8. Van Baelen A, Mottet N, Spahn M, Briganti A, Gontero P, Joniau S. Sense and nonsense of an extended pelvic lymph node dissection in prostate cancer. $A d v$ Urol. 2012; 2012: 983058.

9. Glass EC, Essner R, Giuliano AE. Sentinel node localization in breast cancer. Semin Nucl Med. 1999;29:57-68.

10. Wawroschek F, Vogt H, Weckermann D, Wagner T, Harzmann R. The sentinel lymph node concept in prostate cancer: first results of gamma probe-guided sentinel lymph node identification. Eur Urol. 1999;36:595-600.

11. Wawroschek F, Vogt H, Weckermann D, Wagner T, Hamm M, Harzmann R. Radioisotope guided pelvic lymph node dissection for prostate cancer. J Urol. 2001;166:1715-1719.
12. Briganti A, Larcher A, Abdollah F, et al. Updated nomogram predicting lymph node invasion in patients with prostate cancer undergoing extended pelvic lymph node dissection: the essential importance of percentage of positive cores. Eur Urol. 2012;61:480-487.

13. D'Amico AV, Whittington R, Malkowicz SB, Tomaszewski JE, Schultz D, Wein A. Outcome based staging for clinically localized adenocarcinoma of the prostate. J Urol. 1997;158:1422-1426.

14. Rousseau C, Rousseau T, Bridji B, et al. Laparoscopic sentinel lymph node (SLN) versus extensive pelvic dissection for clinically localized prostate carcinoma. Eur J Nucl Med Mol Imaging. 2012;39:291-299.

15. Rousseau T, Lacoste J, Pallardy A, et al. Laparoscopic sentinel lymph node (SLN) dissection for clinically localized prostate carcinoma: results obtained in the first 70 patients. Prog Urol. 2012;22:30-37.

16. Lécuru F, Mathevet $P$, Querleu D, et al. Bilateral negative sentinel nodes accurately predict absence of lymph node metastasis in early cervical cancer: results of the SENTICOL study. J Clin Oncol. 2011;29:1686-1691.

17. Cagiannos I, Karakiewicz P, Eastham JA, et al. A preoperative nomogram identifying decreased risk of positive pelvic lymph nodes in patients with prostate cancer. J Urol. 2003;170:1798-1803.

18. Jeschke S, Nambirajan T, Leeb K, Ziegerhofer J, Sega W, Janetschek G. Detection of early lymph node metastases in prostate cancer by laparoscopic radioisotope guided sentinel lymph node dissection. J Urol. 2005;173:1943-1946.

19. Häcker A, Jeschke S, Leeb K, et al. Detection of pelvic lymph node metastases in patients with clinically localized prostate cancer: comparison of $\left[{ }^{18} \mathrm{~F}\right]$ fluorocholine positron emission tomography-computerized tomography and laparoscopic radioisotope guided sentinel lymph node dissection. J Urol. 2006;176:2014-2018.

20. Corvin S, Schilling D, Eichhorn K, et al. Laparoscopic sentinel lymph node dissection: a novel technique for the staging of prostate cancer. Eur Urol. 2006;49:280-285.

21. Warncke SH, Mattei A, Fuechsel FG. Z'Brun S, Krause T, Studer UE. Detection rate and operating time required for gamma probe-guided sentinel lymph node resection after injection of technetium- $99 \mathrm{~m}$ nanocolloid into the prostate with and without preoperative imaging. Eur Urol. 2007;52:126-132.

22. Meinhardt W, Valdés Olmos RA, van der Poel HG, Bex A, Horenblas S. Laparoscopic sentinel node dissection for prostate carcinoma: technical and anatomical observations. BJU Int. 2008;102:714-717.

23. Jeschke S, Beri A, Grüll $\mathrm{M}$, et al. Laparoscopic radioisotope-guided sentinel lymph node dissection in staging of prostate cancer. Eur Urol. 2008;53:126-132.

24. Vermeeren L, Valdés Olmos RA, Meinhardt W, et al. Value of SPECT/CT for detection and anatomic localization of sentinel lymph nodes before laparoscopic sentinel node lymphadenectomy in prostate carcinoma. J Nucl Med. 2009;50: $865-870$.

25. Schilling D, Boekeler U, Gakis G, et al. Modified concept for radioisotope-guided sentinel lymph node dissection in prostate cancer. World J Urol. 2010;28:715-720.

26. Vermeeren L, Muller SH, Meinhardt W, Valdés Olmos RA. Optimizing the colloid concentration for improved preoperative and intraoperative image-guided detection of sentinel nodes in prostate cancer. Eur J Nucl Med Mol Imaging. 2010;37:1328-1334.

27. Joniau S, Van den Bergh L, Lerut E, et al. Mapping of pelvic lymph node metastases in prostate cancer. Eur Urol. 2013;63:450-458.

28. Eiriksson LR, Covens A. Sentinel lymph node mapping in cervical cancer: the future? BJOG. 2012;119:129-133.

29. Winter A, Kneib T, Henke RP, Wawroschek F. Sentinel lymph node dissection in more than 1200 prostate cancer cases: Rate and prediction of lymph node involvement depending on preoperative tumor characteristics. Int J Urol. 2014;21:58-63.

30. Heidenreich A, Bellmunt J, Bolla M, et al. EAU guidelines on prostate cancer. Part 1: screening, diagnosis, and treatment of clinically localised disease. Eur Urol. 2011;59:61-71.

31. Jeschke S, Lusuardi L, Myatt A, Hruby S, Pirich C, Janetschek G. Visualisation of the lymph node pathway in real time by laparoscopic radioisotope- and fluorescence-guided sentinel lymph node dissection in prostate cancer staging. Urology. 2012;80:1080-1086.

32. Fujisawa M, Miyake H. Significance of micrometastases in prostate cancer. Surg Oncol. 2008; 17:247-252.

33. Chéreau E, Bezu C, Gligorov J, et al. Impact of immunohistochemical analysis of sentinel lymph node biopsy on breast cancer management. Anticancer Res. 2012;32:3403-3409.

34. Weckermann D, Dorn R, Trefz M, Wagner T, Wawroschek F, Harzmann R. Sentinel lymph node dissection for prostate cancer: experience with more than 1,000 patients. J Urol. 2007;177:916-920. 